\title{
Editorials
}

\section{News on waists, energy density and Eurodiets}

Three recent major statements on the prevention or treatment of food-related chronic diseases, two from the USA and one from Europe, should give us pause, for one reason or another.

\section{Waist is best to assess cardio-metabolic risk}

A position statement from the American Society for Nutrition $^{1-3}$ supports those of us who have always been slightly sceptical about BMI as the best test of body fatness. Doing anthropometric measurements on athletes does that to you! The statement prefers waist circumference for monitoring patients at risk and their response to weightloss programmes, or when taking decisions on which patients should be evaluated for hyperlipidaemia or hyperglycaemia.

The statement also recommends the development of new cut-off levels for waist circumference for use in clinical practice, because the previously suggested levels ${ }^{4}$ have been seen to be of limited value. A number of factors are suggested as necessary to take into account when establishing a more useful waist circumference cut-off level than the present; i.e. gender, age, BMI, race and ethnicity.

This consensus statement should be especially useful in training programmes and in the design of new studies. It provides a nice overview of the measurement technique, the anatomical relationships, the biological mechanisms, and - in particular - the power of waist circumference to predict cardio-metabolic outcomes.

\section{Less energy-dense food - less heavy body}

Reduction in dietary energy density causes weight loss. This is shown once again by results from an American trial $^{5}$. The study investigated the effects of energy density in the diet on health measures, including anthropometry, in three different interventions.

The trick when working on energy density seems to be to exclude the fluid (drinks) content from the calculations, as has been reported earlier ${ }^{6}$. The authors conclude that achievement of considerable weight loss was causally related to reductions in energy density of diets, and that even modest reductions in energy density were associated with reduced body weight.

\section{White paper - should try harder}

A white paper on a strategy for Europe on nutrition and on overweight- and obesity-related health issues ${ }^{7}$ was launched by the European Commission recently, as a follow-up of the 2005 green paper, Promoting Healthy Diets and Physical Activity .

The white paper emphasises the importance of collaborating with industry, and also suggests the set up of a 'high level group' focused on nutrition- and physical activity-related health issues. This group will assess national and regional actions together with the Commission, and disseminate information regarding best practice. The importance of monitoring and surveillance is also very much highlighted.

However, in common with many other national and international policy documents, training of professionals as well as research is more or less forgotten. Higher education and research in public health nutrition should be priorities at European as well as national level. Who otherwise will be working in the monitoring and surveillance systems, if training of high-quality staff is not included? And who will do the quality assurance as well as ensure the evidence base of the best practice, if higher education and research is completely out of the picture?

\section{Agneta Yngve}

Editor-in-Chief

\section{References}

1 Klein S, Allison DB, Heymsfield SB, Kelley DE, Leibel RL, Nonas C, et al. Waist Circumference and Cardiometabolic Risk: A Consensus Statement from Shaping America's Health: Association for Weight Management and Obesity Prevention; NAASO, The Obesity Society; the American Society for Nutrition; and the American Diabetes Association. Obesity (Silver Spring) 2007; 15(5): 1061-7.

2 Klein S, Allison DB, Heymsfield SB, Kelley DE, Leibel RL, Nonas $\mathrm{C}$, et al. Waist circumference and cardiometabolic risk: a consensus statement from Shaping America's Health: Association for Weight Management and Obesity Prevention; NAASO, The Obesity Society; the American Society for Nutrition; and the American Diabetes Association. American Journal of Clinical Nutrition 2007; 85(5): 1197-202.

3 Klein S, Allison DB, Heymsfield SB, Kelley DE, Leibel RL, Nonas $\mathrm{C}$, et al. Waist circumference and cardiometabolic risk: a consensus statement from shaping America's health: Association for Weight Management and Obesity Prevention; NAASO, the Obesity Society; the American Society for Nutrition; and the American Diabetes Association. Diabetes Care 2007; 30(6): 1647-52.

4 Clinical Guidelines on the Identification. Evaluation, and Treatment of Overweight and Obesity in Adults - The Evidence Report. National Institutes of Health. Obesity Research 1998; 6(Suppl. 2): 51S-209S. 
5 Ledikwe JH, Rolls BJ, Smiciklas-Wright H, Mitchell DC, Ard JD, Champagne C, et al. Reductions in dietary energy density are associated with weight loss in overweight and obese participants in the PREMIER trial. American Journal of Clinical Nutrition 2007; 85(5): 1212-21.

6 Ledikwe JH, Blanck HM, Khan LK, Serdula MK, Seymour JD, Tohill BC, et al. Dietary energy density determined by eight calculation methods in a nationally representative United States population. Journal of Nutrition 2005; 135(2): 273-8.

7 Directorate General Health and Consumer Protection, Commission of the European Communities. White Paper on A Strategy for Europe on Nutrition, Overweight and

\section{China calling}

Two interesting papers from the Chinese perspective caught the editor's eye in this issue. The first is on assessment of zinc intake inadequacy ${ }^{1}$, the second on blood folate levels among pregnant Chinese women ${ }^{2}$.

\section{Children and lactating mothers might not get enough zinc}

Almost 70000 subjects, aged 2-101 years, were interviewed for the 2002 China National Nutrition and Health Survey. An added quality with this survey was that, in accordance with suggestions by $\mathrm{WHO}^{2}$, phytate levels were assessed in around 60 foods, selected based on frequency of consumption. The results were then presented as zinc intake as such, zinc density, best food sources and phytate/zinc molar ratio.

The paper shows that average phytate intake in China is higher than that in Western countries. The best sources of zinc were found to be rice and other cereals, followed by animal foods, vegetables and fruits. The groups vulnerable to zinc deficiency were shown to be children, adolescents and lactating women, especially in rural areas.

\section{Folate status in pregnant Chinese women}

The birth prevalence of neural tube defects (NTDs) in China is among the highest in the world. Within China, rural areas with the highest birth prevalence had up to 144 per 10 000. In many countries, NTDs are often diagnosed at an early stage and children aborted - which in a country like my own (Sweden, where folate fortification is not used) results in a reduction in birth prevalence from 6-8 per 10000 born to just above 2 per 10000 .

Recently, a large $s^{3} \mathrm{dy}^{3}$ revealed evidence that also other birth anomalies, such as facial clefts, are related to folate deficiency. More and more information regarding the genetics of folate metabolism polymorphisms, such as those of the gene encoding methylenetetrahydrofolate reductase $(M T H F R)$ is now available, showing its
Obesity Related Health Issues. White Paper from the Commission to the European Parliament, the Council, the European Economic and Social Committee and the Committee of the Regions. Brussels: Commission of the European Communities, 2007.

8 Directorate General Health and Consumer Protection, Commission of the European Communities. Green PaperPromoting Healthy Diets and Physical Activity: A European Dimension for the Prevention of Overweight, Obesity and Chronic Diseases. Brussels: Commission of the European Communities, 2005. importance for maintaining healthy levels of homocysteine ${ }^{4}$.

The purpose of the Chinese study ${ }^{2}$ was to assess blood folate levels in early pregnancy, using two different measures (plasma folate and red-blood-cell folate) in a high-risk (birth prevalence 74 per 10000 ) vs. a low-risk area (4.6 per 10000 ) for NTDs. The results were as might be expected: much lower levels of both measures of folate status were found in the area with a high NTD prevalence. No polymorphism analyses were included in this study, even though previous studies point in the direction of MTHFR C677T polymorphisms being more prevalent in the Chinese high-risk areas for NTDs.

Environmental and behavioural factors revealed in the study to be of importance for a low folate status were living in a rural area, not taking supplements, having a high BMI and smoking. BMI was significantly higher in the rural high-risk area, suggesting the possible effect of increased needs of folate in fatter people, as previously shown ${ }^{5-7}$. This issue may certainly present a threat to many countries where intake of folate is low.

We may see only the tip of the iceberg here, NTDs being only one of the birth anomalies resulting from insufficient folate; early spontaneous abortions, caused by the same problem, are naturally difficult to study. The increased levels of overweight in early pregnancy may also present a larger problem than we could foresee.

We look forward to more information on the measures taken in China to address the problems addressed in these two papers.

Agneta Yngve

Editor-in-Chief

\section{References}

1 Ma G, Li Y, Jin Y, Du S, Kok FJ, Yang X. Assessment of intake inadequacy and food sources of zinc of people in China. Public Health Nutrition 2007; 10(8): 848-54. 
2 Ren A, Zhang L, Hao L, Li Z, Tian Y, Li Z. Comparison of blood folate levels among pregnant Chinese women in areas with high and low prevalence of neural tube defects. Public Health Nutrition 2007; 10(8): 762-8.

3 Wilcox AJ, Lie RT, Solvoll K, Taylor J, McConnaughey DR, Abyholm F, et al. Folic acid supplements and risk of facial clefts: national population based case-control study. British Medical Journal 2007; 334(7591): 464.

4 Bottiger AK, Hurtig-Wennlof A, Sjostrom M, Yngve A, Nilsson TK. Association of total plasma homocysteine with methylenetetrahydrofolate reductase genotypes $677 \mathrm{C}>\mathrm{T}, 1298 \mathrm{~A}>\mathrm{C}$, and $1793 \mathrm{G}>\mathrm{A}$ and the corresponding haplotypes in Swedish children and adolescents. International Journal of Molecular Medicine 2007; 19(4): 659-65.

5 Mojtabai R. Body mass index and serum folate in childbearing age women. European Journal of Epidemiology 2004; 19(11): 1029-36.

6 Ray JG, Vermeulen MJ, Meier C, Wyatt PR. Risk of congenital anomalies detected during antenatal serum screening in women with pregestational diabetes. QJM: Monthly Journal of the Association of Physicians 2004; 97(10): 651-3.

7 Ray JG, Wyatt PR, Vermeulen MJ, Meier C, Cole DE. Greater maternal weight and the ongoing risk of neural tube defects after folic acid flour fortification. Obstetrics and Gynecology 2005; 105(2): 261-5. 